\title{
THE ROLE OF COGNITIVE CONTROL AND RUMINATION IN PREDICTING DEPRESSION AMONG ADOLESCENTS WITH INTERNALIZING DISORDERS
}

\author{
Sanja Jandrić ${ }^{1,2}$, Pavo Filaković ${ }^{3}$, Ana Kurtović4 ${ }^{4}$ Vlatka Kovač ${ }^{1}$, Domagoj Benić ${ }^{1}$, \\ Stanislav Rogulja ${ }^{1}$ \& Katarina Dodig-Ćurković ${ }^{1,2,3}$ \\ ${ }^{1}$ Unit for Child and Adolescent Psychiatry, University Hospital Center Osijek, Osijek, Croatia \\ ${ }^{2}$ Faculty of Medicine, Josip Juraj Strossmayer University of Osijek, Osijek, Croatia \\ ${ }^{3}$ Faculty of Dental Medicine and Health, Josip Juraj Strossmayer University of Osijek, Osijek, Croatia \\ ${ }^{4}$ Department of Psychology, Faculty of Humanities and Social Sciences, Josip Juraj Strossmayer University of Osijek, \\ Osijek, Croatia
}

received: 14.7.2020;

revised: 15.9.2020;

accepted: 16.12 .2020

\section{SUMMARY}

Background: Given the high prevalence of internalizing disorders among adolescents, it is necessary to define the factors affecting the development and course of psychopathology. Nolen Hoeksema demonstrated the effect of rumination on the development of various forms of psychopathology in adults, while recent data suggest that cognitive control may be a factor underlying this relationship. The aim of this study is to investigate the relation between cognitive control impairments and symptoms of depression through rumination in adolescents suffering from internalizing psychiatric disorders.

Subjects and methods: The study included 100 adolescents of both genders diagnosed with internalizing psychiatric disorders at the Unit for Child and Adolescent Psychiatry at University Hospital Center Osijek. During psychodiagnostic assessment, subjects completed Youth self report, CANTAB Intra-dimensional/extra-dimensional (IED) task, The Ruminative Response Scale, and Beck Depression Inventory-II.

Results: The results indicate a clinically significant level of internalizing symptoms and a clinically and subclinically high level of depressive symptoms. The results also show a high positive correlation between internalizing symptoms, rumination, and depressive symptoms, as well as a positive correlation between female gender and internalizing symptoms, rumination, and depressive symptoms. Significant predictors of depression are female gender and rumination while cognitive control has not been detected as a significant predictor.

Conclusion: The results of the study emphasize the importance of rumination in the prediction of depressive symptoms in internalizing psychiatric disorders among adolescents and, accordingly, the importance of rumination as a clinical variable in terms of implications in the prevention and treatment of internalizing psychopathology.

Key words: internalizing psychopathology - cognitive control - rumination - depression - adolescents

$$
\text { * } * * * * *
$$

\section{INTRODUCTION}

Adolescence is a formative period marked by intense processes of maturation which aim to develop a healthy personality adapted to cultural norms. Although this period of progressive transformation provides an opportunity for successful adaptation, in a number of adolescents this period can presents a challenge for adaptation. Accordingly, adolescence represents a critical developmental period with increased clinical interests given that many mental disorders that occur in adulthood actually arise during adolescence (Kessler et al. 2007). According to the dimensional model of adolescent psychopathology, internalizing disorders incorporates a variety of negative emotions and distress, which are intrapsychically oriented. Disorders from the internalizing spectrum include anxiety disorders, depression, social withdrawal, and somatization. They are characterized by chronicity through a developmental perspective. The disorders have a multifactorial pathogenesis and high com- orbidity, and they cause significant functional and interpersonal impairments during adolescence. In a study by Merikangas et al. (2010) on a sample of over 10,000 adolescents, the results showed that the prevalence of mood disorders among adolescents was $14.3 \%$, while the prevalence of anxiety disorders was $31.9 \%$, and both were higher in female than in male adolescents.

Within the framework of modern developmental psychopathology, the diathesis stress model presume that the onset of psychiatric disorder can be triggered by stressful life events in individuals who have certain predispositions to those disorders. The model emphasizes the dynamic interaction between personal and contextual predisposing factors, with stress as a precipitating factor in the development of psychopathology. According to this model, the relationship between risk and protective factors has significant causal implications in the incidence, course and remission of the disorder, with a larger number of risk factors relating to more serious psychopathology. 
Adolescence is a critical period for the development of depression, and its levels increase dramatically through the period from mid to late adolescence when they reach adulthood levels (Merikangas et al. 2010). At the same time, many adolescents experience subclinical symptoms of depression, which also represent a source of significant suffering and impairment (Aalto-Setälä et al. 2014).

Cognitive control, as a higher-order mental process, controls and regulates lower-order processes (Miyake \& Friedman 2012). Particularly, it affects the ability to control and inhibit impulsive automatic responses/impulsive action, generates adaptive solutions and complex behaviors, and, at the same time, it controls negative emotions and delays gratification in order to achieve adaptive developmental outcomes (McIntyre et al. 2013). Cognitive control develops during childhood and adolescence. It has a significant superior functionalregulatory role in cognitive processes, emotions, behavior, and social functioning, and it reaches its peak during early adulthood. The findings of previous studies of cognitive control as a transdiagnostic risk factor for psychopathology suggest that cognitive control deficits underlie all psychiatric disorders in adults (Caspi et al. 2014). Following these findings, research in the field of developmental psychopathology in recent years has focused on the role of cognitive control in the etiology of different forms of psychopathology in children and adolescents, investigating the mechanisms through which deficits in cognitive control affect etiology, clinical course and treatment outcomes of disorders. Nevertheless, the specific mechanisms that lead individuals with low cognitive control to experience higher levels of psychopathology symptoms remain largely unknown. Accordingly, Hardin et al. (2007), in a clinical study found that adolescents diagnosed with anxiety disorder and depression, had significantly poorer performance on the cognitive control tasks compared to healthy adolescents,

Cognitive strategies, which adolescents use to cope with stressors and to regulate their emotions in response to life stress were shown to be an important risk factor for the development of psychopathology. In the field of developmental psychopathology less attention has been directed at the potential role of cognitive-emotional regulation processes such as ruminative response style. Empirically, the most widely used and conceptualized model of rumination is found within The Response Styles Theory (Nolen-Hoeksema 1991). According to this model, ruminations are defined as negative, intrusive, repetitive thoughts about the causes, symptoms and consequences of currently present unpleasant emotions. Also, rumination involve keeping negative information in working memory (Hilt 2014). The results of recent studies suggest robust association between rumination and stress (LeMoult 2013) and the impact of rumination on anxiety disorders in adults (McLaughlin \& Nolen-Hoeksema 2011, Fresco et al. 2002, Harrington
\& Blankenship 2002, Mellings \& Alden 2000). Among adolescents suffering from internalizing disorders, lower perceptions of peer support and higher levels of peer rejection, frequent peer conflicts, and perceptions of poor quality friendships were associated with greater rumination (McLaughlin 2012). Furthermore, Shapero et al. (2013) found that a greater tendency to ruminate was associated with emotional abuse by parents or peer in a sample of adolescent suffering from internalizing disorders

Previous studies have investigated the effects of experimentally induced ruminations on cognitive tasks that included effective focus attention, attentional shifting and problem solving. Results have showed that those with a greater tendency to ruminate demonstrated lower levels of cognitive control, as well as a negative effect of rumination on almost all cognitive tasks (Lubomirsky \& Tkach 2004, Eshun 2000. Lyubomirsky et al. 1999). Recent studies have examined the relation between rumination and cognitive control in adults, while a small number of studies have examined this relation in adolescents. To our knowledge, there are no studies examining the association in clinical sample of adolescents. In line with this, the aim of this study is to examine a new process model linking cognitive control impairments to symptoms of depression via rumination in adolescents suffering from internalizing disorders.

\section{SUBJECTS AND METHODS}

\section{Subjects}

The study is cross sectional and was conducted in the Psychological Clinic of the Unit for Child and Adolescent Psychiatry of the University Hospital Center Osijek. The research was approved by the Ethics Committee of the University Hospital Center Osijek and the Ethics Committee of the Faculty of Medicine Osijek. Inclusion criteria were as follows: (1) subjects aged from 12 to 18 years both gender, (2) indicated for psychodiagnostic assessment after the first psychiatric examination diagnosis of 32 Depressive episode, F40-F48 Neurotic, stress-related and somatoform disorders, F93 Emotional disorders with onset specific to childhood according to the International Classification of Diseases ICD-10 criteria confirmed through Structured Clinical Interview and Croatian as a native language. Exclusion criteria were: (1) IQ score lower than 70, (2) adolescent crisis with psychotic symptoms; (3) refusal to sign informed consent by the subject or their parent, (4) existence of an organic disorder such as a brain tumor, severe epilepsy, or other impairment. Before the beginning of the research, the purpose and goal of the research and the manner of its implementation were explained to each respondent in detail orally and in writing. Written consent was then sought from subjects to participate in the study, which was signed at their own discretion by adolescents over the age of 16 and for all other adolescents by one of the parents. 


\section{Methods} used:

The following psychodiagnostic procedures were

- For the purpose of the study we used the Croatian translations of the Youth Self-Report (Achenbach \& Rescorla 2001). Youth Self Report is a questionnaires assess internalizing and externalizing problems during the past six months on a 3 -point scale $(0=$ not true; $1=$ somewhat/sometimes true; $2=$ very/often true) with a higher score indicating a higher manifestation of the problem. For purposes of examining subjects' symptoms from a dimensional framework (internalizing disorders), only the scores referring to internalizing symptoms were used (31 items corresponding to the Anxious/Depressed, Withdrawn and Somatic Complaints subscales). Varied studies have shown good to excellent Cronbach's alpha scores for the eight empirically-based syndrome scales (Achenbach \& Rescorla 2001) and Cronbach's Alpha coefficients in our study was 0.91 .

- Participants completed task from the Cambridge Neuropsychological Test Automated Battery the Intra-Extra Dimensional Set Shift Test (IED) which is a computerized analogue of the Wisconsin Card Sorting Test and is used to examine general cognitive control during a non-emotional task. Measure of cognitive control is represent as total errors or stages completed.

- Croatian translation (Kalebić-Jakupčević 2014) of the Ruminative Response Scale (Nolen-Hoeksema \& Morrow 1991) was used to measure rumination. The scale was originally constructed as a subscale of the Response Styles Questionnaires. It consists of 22 items measuring different reactions to depressed mood, mulling over depressive symptoms and reflecting over their meaning. The scale has good internal reliability (Nolen-Hoeksema \& Morrow 1991), and Cronbach's Alpha coefficients in our study was 0.90 .

- Croatian translation (Matešić \& Ružić 2009) of Beck Depression Inventory-II (BDI-II) (Beck et al. 1996) was used to measure symptoms of depression. It is a 21-item Likert-type self-report measure of depressive symptomology. Beck et al. (1996) reported Cronbach's Alpha coefficients of 0.93 in a sample of college students, and 0.92 in psychiatric outpatients, and Cronbach's Alpha in our study was 0.95.

\section{Statistical analysis}

In statistical analysis, in order to examine the levels of internalizing symptoms, rumination, depression and cognitive control descriptive statistics were calculated. Frequency and percentage of gender and diagnosis were calculated. In order to examine the correlations between internalizing symptoms, rumination, cognitive control and depression, Pearson correlation coefficients were used. In order to examine the correlations bet- ween age and gender with internalizing symptoms, rumination, cognitive control, depression, Spearman correlation coefficients were used. Finally, in order to examine whether depression can be predicted by age, gender rumination and cognitive control, hierarchical regression analyses were used. The level of significance was 0.05. Statistical program SPSS (16.0, SPSS Inc, Chicago, IL, USA) was used for statistical analysis.

\section{RESULTS}

Participants mean (SD) age was 15.09 (1.60) ranging from 12 to 18 years. Out of a total of 100 adolescents, $35 \%$ were male and $65 \%$ were female, with mean age 15.09 (standard deviation age 1.60) ranging from 12 to 18 years. The majority of adolescents, $59 \%$ of them were diagnosed with Neurotic, stress-related and somatoform disorders, $38 \%$ of them were diagnosed with Emotional disorders with onset specific to childhood, and 3\% were diagnosed with Depressive episode using an International Classification of Diseases, $10^{\text {th }}$ Revision (ICD-10) (Table 1).

Table 1. Sample characteristics for group of adolescents with internalizing psychopatology

\begin{tabular}{lc}
\hline Demographic variable & $\mathrm{N}(\%)$ \\
\hline Age (standard deviation) & $\mathrm{M}(\mathrm{SD})$ \\
\hline & \\
\hline Gender (\%) & $35(35 \%)$ \\
Male & $65(65 \%)$ \\
Female & \\
Disorder (ICD-10) & $59(59 \%)$ \\
Neurotic, stress-related and & $38(38 \%)$ \\
somatoform disorders & \multicolumn{1}{c}{$3(3 \%)$} \\
Emotional disorders with onset & \\
specific to childhood & \\
Depressive episode & \\
\hline & Data are presented as number (percentage) of participants \\
if not stated otherwise; M - arithmetic mean; \\
SD - standard deviation; ICD-10= International \\
Classification of Diseases, 10 ${ }^{\text {th }}$ revision
\end{tabular}

As can be seen in Table 2 the participants average score suggest clinical high levels of internalizing symptoms $(\mathrm{M}=21.75, \mathrm{SD}=12.04)$, and mostly moderate to severe depression symptoms $(\mathrm{M}=19.29, \mathrm{SD}=13.32)$. $\mathrm{Re}-$ garding cognitive control, mean values were medium for total errors $(M=45.82, S D=29.11)$ and high for stages completed $(\mathrm{M}=7.86, \mathrm{SD}=1.31)$.

In order to examine correlations between variables Pearson's and Spearman's correlation coefficients were calculated. Internalizing symptoms are significantly highly positively correlated with rumination $(\mathrm{r}=0.81$, $\mathrm{p}<0.01)$ and depression $(\mathrm{r}=0.87, \mathrm{p}<0.01)$. Rumination is significantly highly positively correlated with depression $(\mathrm{r}=0.82, \mathrm{p}<0.01)$. 
Table 2. Descriptive statistics and intercorreleations among varibles $(\mathrm{N}=100)$

\begin{tabular}{lcccccc}
\hline Measure & 1. & 2. & 3. & 4. & 5. & 6. \\
\hline Internalizing symptoms & - & & & & & \\
Rumination & $0.81^{* *}$ & - & & & & \\
Total errors & -0.15 & -0.06 & - & & & \\
Stages completed & 0.09 & 0.02 & $-0.95^{* *}$ & - & & - \\
Depression & $0.87^{* *}$ & $0.82^{* *}$ & -0.14 & 0.10 & - & 0.08 \\
Gender & $0.30^{* *}$ & $0.24^{* *}$ & 0.04 & -0.03 & $0.22^{*}$ & - \\
Age & 0.16 & 0.09 & 0.08 & -0.16 & 0.08 & \\
Mean & 21.75 & 46.60 & 45.82 & 7.86 & 19.29 & \\
SD & 12.04 & 14.93 & 29.11 & 1.31 & 13.32 & \\
Range (min-max) & $1-56$ & $22-88$ & $9-185$ & $2-9$ & $0-58$ & \\
\hline
\end{tabular}

Note: $* \mathrm{p}<0.05 ; \quad * * \mathrm{p}<0.01$

Table 3. Hierarhical regression analyses predicting depression in group of adolescents with internalizing psychopatology $(\mathrm{N}=100)$

\begin{tabular}{|c|c|c|}
\hline & \multicolumn{2}{|c|}{ Depression } \\
\hline & $\Delta \mathrm{R}^{2}$ & $\beta$ \\
\hline \multicolumn{3}{|l|}{ Predictor } \\
\hline Step 1 & $0.068 *$ & \\
\hline Gender & & $0.23 *$ \\
\hline Age & & 0.09 \\
\hline Step 2 & 0.032 & \\
\hline Total errors & & -0.40 \\
\hline Stages completed & & -0.26 \\
\hline Step 3 & $0.596 * *$ & \\
\hline Rumination & & $0.81 * *$ \\
\hline Adjusted $\mathrm{R}^{2}$ & 0.677 & \\
\hline$F(d f)$ & $35.74(1.99)$ & \\
\hline
\end{tabular}

Total errors and stages completed were not significantly correlated with either criterion, except negatively correlated among themselves $(\mathrm{r}=-0.95, \mathrm{p}<0.01)$.

Gender is significantly positively correlated with internalizing symptoms $(\mathrm{r}=0.30, \mathrm{p}<0.01)$, rumination $(\mathrm{r}=0.24, \mathrm{p}<0.01)$ and depression $(\mathrm{r}=0.22, \mathrm{p}<0.05)$. The correlations are low, ranging from 0.22 to 0.30 .

In order to examine whether gender, age, cognitive control and rumination can predict symptoms of depression in adolescents with internalizing disorders, hierarchical regression analysis were used. As can be seen in table 3 , gender $(\beta=0.23, p<0.05)$ and rumination $(\beta=0.81, p<0.01)$ were significant positive predictors of depression. Total errors and stages completed, as measures of cognitive control, did not contribute significantly to depression. Overall percentages of total variance explained by predictors was high $\left(\Delta \mathrm{R}^{2}=0.67\right)$.

\section{DISCUSSION}

The diathesis stress model of psychopathology provides a complex picture of a number of factors that contribute to developmental outcomes in youth. To our knowledge, only a few studies to date have examined the effect of cognitive control and rumination on the development of psychopathology in adults. The results of previous research suggest an association between cognitive control deficits and high levels of rumination in dysphoric and depressed adults (Altamirano et al. 2010, Davis \& Nolen-Hoeksema 2000). In line with this, Demeyer et al. (2012) found a mediating role of rumination in the effect of cognitive control deficits on the level of depressive symptoms in a small sample of adult patients suffering from depressive disorder. They also found that patients demonstrate cognitive control deficits only during the acute phase of the disorder. A small number of studies have investigated these constructs in adolescents and youth samples, showing quite inconsistent results (Alta du Pont et al. 2019). In a study by Snyder et al. (2019) the results have shown an association between poor cognitive control and general factor of psychopathology via high levels of stress and subsequent rumination, suggesting that cognitive control deficits are associated with rumination only indirectly through stress generation. In contrast, in a study provided by Alta du Pont et al. (2020) the results did not confirm mediating role of rumination between individual components of cognitive control and psychopathological symptoms. To our knowledge, this is the first study to examine cognitive control, rumination, and depressive symptoms in a clinical sample of adolescents. The aim of the study was to examine the effect of cognitive control deficits on the symptoms of depression via rumination in adolescents suffering from internalizing disorders.

At the exploratory descriptive level of analysis, levels of adolescents internalizing symptoms is above the cut-off point, which refers to clinically and sub-clinically significant levels of symptoms. The symptoms include of excessive inhibition, anxiety, fear, sadness, depression, somatic complaints, and social withdrawal, which cause significant functional and interpersonal impairments. The results are in line with previous studies (Sandoval et al 2006, Achenbach \& Rescorla 2001, Roussoss et al. 2001). The high association between internalizing symptoms and rumination in our adolescents sample follows the findings of previous studies that found 
an association between rumination and negative mood in healthy adolescents (Nolen-Hoeksema et al. 2007), and especially in depressed adult patients (Watkins 2009).

The directions of correlations between variables suggest that female gender is correlated with higher levels of internalizing symptoms, rumination and depressive symptoms. Findings from previous studies examining the role of gender in the etiology of developmental psychopathology provide inconsistent results, with some studies not finding any significant gender differences in emotional and behavioral problems in adolescents (Marin et al. 2018), while other studies emphasize female gender as a risk factor for the development maladaptive strategies which affect psychological adjustment and increase the risk for internalizing disorders (eg, Hammen \& Brennan 2001) and depression (Pawlby et al. 2009, Milne \& Lancaster 2001). Although according to Rescorla et al. $(2007 \mathrm{a}, \mathrm{b})$ gender is one of the strongest risk factors for internalizing and externalizing problems, its relative contribution remains unclear. According to previous theoretical knowledge and framework, female adolescents internalize their problems and negative emotions as a part of basic psychological processes which can result in withdrawal, loneliness, anxiety and depression, while male adolescents more often externalize their emotions and express them through aggressive and impulsive behaviors. However, understanding the role of gender in regard to other risk factors (such as depressed parent, low IQ, traumatic experiences, poverty, peer abuse) in the context of maladaptive adjustment can help design treatment programs (Garber \& Downs 2011, Sheeber et al. 2002). Also, Aldao and Nolen-Hoeksema (2012), in a meta-analytic review, showed that higher levels of rumination in females, compared to males, represent a mediating effect on the level of depression that becomes visible in the postpubertal period.

Contrary to our expectations, our results did not support the hypothesis of the impact of cognitive control deficits on the level of depression through the mediating role of rumination in adolescents suffering from internalizing psychiatric disorders. The effects of cognitive control on the level of depression are small and insignificant, and the findings could be interpreted in several ways. Previous research provides inconsistent conclusions about the effects of cognitive control on the level of psychopathological symptoms, depending on how the cognitive control construct is operationalized in the study. Hilt et al. (2012) examined the effect of cognitive control deficits on the level of emotional problems in adolescents through rumination. Their research used two measures of cognitive control. The results showed that cognitive control, measured using neutral tasks, showed no correlation or predictive effect on the level of emotional problems, neither directly nor indirectly through ruminations. In contrast, a measure of cognitive control examined using negative emotional tasks showed inhibition deficits and was associated with ruminations. We could explain our results in the light of the findings of this study. Namely, in our research we investigate cognitive control using a neutral task. It is possible that negative emotional tasks of cognitive control capture deficits in internalizing disorders more than neutral tasks of cognitive control. Accordingly, Demeyer et al. (2012) found the effect of cognitive control, examined only by affective tasks, but not by neutral tasks. Also, in a study by Snyder and Hankin (2016) cognitive control deficits measured using nonemotional neutral tests were associated with psychopathological symptoms only indirectly, through the impact of stress generation.

Another explanation for these results may be found in the fact that adolescence is a formative developmental period in which cognitive control has not yet established its dominance over cognitive control components due to incomplete processes of brain maturation, especially the structures of the prefrontal cortex that mature last. Interactive component model of cognitive control emphasizes that there is one general superior function of cognitive control that regulates and integrates core components of cognitive control (Miyake \& Friedman 2012). According to Luna et al. (2015) effective cognitive control improves through adulthood by increasing the flexible integration of its parts, including inhibitory control, performance monitoring, and working memory. Although dramatic changes in the performance of cognitive control occur in individuals through childhood to adolescence, cognitive control in adolescence is more variable than in adulthood. Accordingly, performance on cognitive control tasks still develops during adolescence, and it is to be expected that the risk pathways of cognitive control and psychopathology change during development (Zanolie \& Crone 2018).

Since the mechanisms by which cognitive control deficits increase the risk for psychopathology in adolescents remain unclear, it would be interesting to examine the relationship between individual components of cognitive control and symptoms of internalizing psychopathology. Furthermore, deficits in components of cognitive control might shed light on the mediating role of rumination in internalizing psychopathology and help to understand how impairments of cognitive control components contribute to the development of psychiatric disorders in adolescents and increase their comorbidity.

Although the primary goal of the study was greater understanding of the relation between cognitive control deficits and internalizing psychopathology in adolescents, the findings provided us with new insights into the effect of rumination on internalizing psychopathology. Our results have shown that rumination has an extremely large effect on the level of depression in internalizing disorders. Previous studies have demonstrated the role of rumination in the etiology and maintenance of depressive disorders in adult patients (Watkins \& Brown 2002, Watkins \& Teasdale 2001, Nolen-Hoeksema 2000), while studies conducted on a population of healthy adolescents has examined their 
relation to symptoms of depression (Hanklin 2008) and posttraumatic stress (Jennes et al. 2016). We do not find clinical studies examining the effect of rumination on depression among adolescents suffering from internalizing disorders. In fact, the effect of rumination on depressive symptoms in this study is extremely large and it is very likely that adolescents with clinically high levels of internalizing symptoms repeatedly focus on negative thoughts and experiences, which further impairs behavior and affective experiences, and therefore results in clinically high levels of depression (NolenHoeksema \& Watkins 2011). It is possible that rumination increases the level of depression through multiple mechanisms, including prolonging negative moods by focusing on depressive experiences and repeated negative thoughts, while impairing adaptive, positive coping strategies such as problem solving. The ability to focus attention on important information and suppress irrelevant information seems to be critical in avoiding the vicious circle of repetitive thoughts. The ability of adolescents to regulate and control their own emotions can influence whether their developmental pathways will be more or less adaptive and further establish coping patterns and strategies that can continue into adulthood (Strauman \& Eddington 2017, Berking et al. 2013).

Accordingly, evaluation of cognitive coping strategies in adolescents suffering from internalizing disorders is necessary in order to modify maladaptive style of coping and prevent continuity and chronicity through adulthood (Sloan et al. 2017). Given the scientifically proven effectiveness of mindfulness techniques in reducing rumination (Svendsen et al. 2017), these guidelines should be followed when designing treatment interventions. At the same time, there is evidence that positive self-focus attention is associated with lower levels of depression (Feldman et al. 2008), and these findings should be considered when applying mindfulness techniques and other treatment interventions.

The significance of this study is in emphasizing the importance of rumination in the development of internalizing psychopathology, which could be of use in creating more efficient and complex treatments and interventions intended for adolescents. Also, the vast majority of research have studied rumination in individual psychiatric disorders or in relation to individual symptoms, without taking the pattern across disorders into account, and for this reason this research represents a significant scientific contribution.

In future research, it would be important to investigate cognitive control over emotional information among adolescent population, especially in clinical samples of adolescents, and to identify other specific cognitive emotion regulation strategies in order to shed light on their impact on internalizing psychopathology. Also, since depression and anxiety often occur in comorbidity and hierarchical models of psychopathology continuously prove their common variance within internalizing disorders, and despite the significant differences between depression and anxiety in research, common risk factors are continuously confirmed. In line with it, it would be interesting to examine the effects of cognitive control and rumination on the symptoms of anxiety in internalizing disorders.

\section{CONCLUSION}

The current study found no evidence that cognitive control over non emotional information is associated with depressive symptoms via rumination among adolescent with internalizing psychopathology. Result showed extremely large predictive effect of gender and rumination on depressive symptoms suggesting that adolescents with internalizing psychiatric disorders repeatedly focus on negative thoughts and experiences, which further impair behavior and affective experiences and therefore results in clinically high levels of depression which may underlie this vicious cycle. Identifying youth with specific cognitive risk factors and further investigating deficits of cognitive control components can enhance our knowledge and help us understand how these factors relate to the etiology of internalizing psychopathology within the developmental context. Findings can help us detect youth at risk and also create effective treatment programs and preventive interventions.

\section{Acknowledgements: None.}

\section{Conflict of interest: None to declare.}

\section{Contribution of individual authors:}

Sanja Jandrić: Study conception and design; planning and designing data acquisition, conducting data acquisition process, analysis and interpretation of data; drafting of manuscript;

Pavo Filaković: planning and designing data acquisition, drafting of manuscript; critical revision;

Ana Kurtović: planning and designing of the data acquisition, critical revision;

Vlatka Kovač: conducting data, acquisition process; Domagoj Benić: conducting data, acquisition process; Stanislav Rogulja: conducting data, acquisition process; Katarina Dodig-Ćurković: planning and designing data acquisition, critical revision.

\section{References}

1. Aalto-Setala T, Marttunen M, Tuulio-Henriksson A, Poikolainen $K$ \& Lonnqvist J: Depressive symptoms in adolescence as predictors of early adulthood depressive disorders and maladjustment. Am J Psychiatry 2002; 159:1235-1237. doi:10.1176/appi.ajp.159.7.1235

2. Achenbach $T \&$ Rescorla L: The Manual for the ASEBA School-Age Forms \& Profiles. Burlington: University of Vermont, Research Center for Children, Youth, and Families, 2001 
3. Aldao A \& Nolen-Hoeksema S: When are adaptive strategies most predictive of psychopathology? Journal of Abnormal Psychology 2012; 121:276-281. https://doi.org/10.1037/a0023598

4. Altamirano LJ, Miyake A \& Whitmer AJ: When mental inflexibility facilitates executive control: beneficial side of ruminative tendencies on goal maintenance. Psychol Sci 2010; 21:1377-1382. doi:10.1177/0956797610381505

5. Beck AT, Steer RA, Brown GK. Manual for the Beck Depression Inventory-II. San Antonio, TX: Psychological Corporation, 1996

6. Berking M, Ebert D, Cuijpers $P$ \& Hofmann SG: Emotion regulation skills training enhances the efficacy of inpatient cognitive behavioral therapy for major depressive disorder: A randomized controlled trial. Psychotherapy and Psychosomatics 2013; 82:234-245. doi:10.1159/000348448

7. Caspi A, Houts RM, Belsky DW, et al.: The p factor: one general psychopathology factor in the structure of psychiatric disorders? Clin Psychol Sci 2014; 2:119-137

8. Davis $R N \&$ Nolen-Hoeksema S: Cognitive inflexibility among ruminators and non ruminators. Cognitive Therapy \& Research 2000; 24:699-711.

http://dx.doi.org/10.1023/A:1005591412406

9. Demeyer I, De Lissnyder E, Koster EH, Raedt R: Rumination mediates the relationship between impaired cognitive control for emotional information and depressive symptoms: a prospective study in remitted depressed adults. Behaviour Research and Therapy 2012; 50:292-297

10. Du Pont A, Karbin Z, Rhee SH, Corley RP, Hewitt JK \& Friedman NP: Differential associations between rumination and intelligence subtypes. Intelligence 2020; 78:101420. doi:10.1016/j.intell.2019.101420

11. Du Pont A, Rhee SH, Corley RP, Hewitt JK, Friedman $N P$ : Rumination and executive functions: Understanding cognitive vulnerability for psychopathology. Journal of Affective Disorders 2019; 256:550-559. doi:10.1016/j.jad.2019.06.026

12. Du Pont A, Rhee SH, Corley RP, Hewitt JK, Friedman NP: Rumination and Psychopathology: Are Anger and Depressive Rumination Differentially Associated with Internalizing and Externalizing Psychopathology? Clin. Psychol Sci 2018; 6:18-31

13. Eshun S: Role of gender and rumination in suicide ideation: A comparison of college samples from Ghana and the United States. Cross-Cultural Research 2000; 34:250-263

14. Feldman GC, Joormann J, Johnson SL: Responses to positive affect: A self-report measure of rumination and dampening. Cognitive Therapy and Research 2008; 32:507-525. doi:10.1007/s10608-006-9083-0

15. Fresco DM, Frankel A, Mennin DS, Turk CL, Heimberg $R G$ : Distinct and overlapping features of rumination and worry: The relationship of cognitive production to negative affective states. Cognitive Therapy and Research $2002 ; 26: 179-188$

16. Garber $J \&$ Downs LE: Prevention of depression in youth: Sex differences in effects. In T. J. Strauman, P. R. Costanzo, \& J. Garber (Eds.), Duke series in child development and public policy. Depression in adolescent girls: Science and prevention (p. 193-234). The Guilford Press, 2011

17. Hammen C, Brennan P: Depressed adolescents of depressed and nondepressed mothers: Tests of an interpersonal impairment hypothesis. Journal of Consulting and Clinical Psychology 2001; 69:284-294
18. Hankin BL: Rumination and depression in adolescence: investigating symptom specificity in a multiwave prospective study. Journal of Clinical Child and Adolescent Psychology 2008; 37:701-713

19. Hardin MG, Schroth E, Pine DS \& Ernst M: Incentiverelated modulation of cognitive control in healthy, anxious, and depressed adolescents: Development and psychopathology related differences. Journal of Child Psychology and Psychiatry 2008; 48:446-454

20. Harrington JA, Blankenship V: Ruminative thoughts and their relation to depression and anxiety. Journal of Applied Social Psychology 2002; 32:465-485

21. Hilt LM, Leitzke BT \& Pollak SD: Cognitive control and rumination in youth: The importance of emotion. Journal of Experimental Psychopathology 2014; 5:302-313. https://doi.org/10.5127/jep.038113

22. Hilt LM, Armstrong JM, Essex MJ: Early family context and development of adolescent ruminative style: Moderation by temperament. Cognition and Emotion 2012; 26:916-926. http://dx.doi.org/10.1080/02699931.2011.621932

23. Jenness JL, Jager-Hyman S, Heleniak C, Beck AT, Sheridan MA, McLaughlin KA: Catastrophizing, rumination, and reappraisal prospectively predict adolescent PTSD symptom onset following a terrorist attack. Depress Anxiety 2016; 33:1039-47

24. Kessler RC, Amminger GP, Aguilar-Gaxiola S, Alonso J, Lee S, Ustun TB: Age of onset of mental disorders: a review of recent literature. Curr Opin Psychiatry 2007; 20:359-64

25. McIntyre RS, Cha DS, Soczynska JK, Woldeyohannes HO, Gallaugher LA, Kudlow P, et al: Cognitive deficits and functional outcomes in major depressive disorder: determinants, substrates, and treatment interventions. Depress Anxiety 2013; 30:515-527

26. LeMoult J, Arditte KA, D'Avanzato C \& Joormann J: State rumination: Associations with emotional stress reactivity and attention biases. Journal of Experimental Psychopathology 2013; 4:471-484. https://doi.org/10.5127/jep.029112

27. Lyubomirsky $S \&$ Tkach $C$. The consequences of dysphoric rumination. In: Papageorgiou $C \&$ Wells $A$ (eds): Depressive Rumination: Nature, Theory, and Treatment, 2141. Chichester, England: John Wiley \& Sons Ltd, 2004

28. Lyubomirsky S, Caldwell ND \& Nolen-Hoeksema $S$ Effects of ruminative and distracting responses to depressed mood on the retrieval of autobiographical memories. Journal of Personality and Social Psychology 1998; 75:166-177

29. Kalebić Jakupčević K: Provjera uloge metakognitivnih vjerovanja, ruminacije, potiskivanja misli i usredotočenosti u objašnjenju depresivnosti. Doktorski rad. Filozofski fakultet, Sveučilište u Zagrebu, Zagreb, 2014

30. Luna B, Marek S, Larsen B, Tervo-Clemmens B \& Chahal $R$ : An integrative model of the maturation of cognitive control. Annual Review of Neuroscience 2015; 38:151-170. https://doi.org/10.1146/annurev-neuro-071714-034054

31. Marin AH, Borba BMR \& Bolsoni-Silva AT: Emotional and behavioral problems and school repetition: A casecontrol study with adolescents. Psicologia: Teoria e Prática 2018; 20:299-313

32. McLaughlin KA \& Nolen-Hoeksema S: Rumination as a trans- diagnostic factor in depression and anxiety. Behaviour Research and Therapy 2011; 49:186-193. http://dx.doi.org/10.1016/j.brat.2010.12.006 
33. Mellings TM \& Alden LE: Cognitive processes in social anxiety: the effects of self-focus, rumination and anticipatory processing. Behav. Res. Ther 2000; 38:243-257

34. Merikangas KR, He JP, Burstein M, Swanson SA, Avenevoli $S$, Cui L, et al: Lifetime prevalence of mental disorders in U.S. adolescents: results from the National Comorbidity Survey Replication - Adolescent Supplement (NCS-A). J Am Acad Child Adolesc Psychiatry 2010; 49:980-9

35. Milne LC \& Lancaster S: Predictors of depression in female adolescents. Adolescence 2001; 36:207-223

36. Miyake $A \&$ Friedman NP: The nature and organization of individual differences in executive functions: Four general conclusions. Current Directions in Psychological Science 2012; 21:8-14. https://doi.org/10.1177/0963721411429458

37. Nolen-Hoeksema $S \&$ Watkins ER: A heuristic for developing transdiagnostic models of psychopathology: Explaining multifinality and divergent trajectories. Perspectives on Psychological Science 2011; 6:589-609

38. Nolen-Hoeksema S, Stice E, Wade E \& Bohon C: Reciprocal relations between rumination and bulimic, substance abuse ad depressive symptoms in female adolescents. Journal of Abnormal Psychology 2007; 116:198-207

39. Nolen-Hoeksema S: The role of rumination in depressive disorders and mixed anxiety/depressive symptoms. Journal of Abnormal Psychology, 2000; 109:504-511. https://doi.org/10.1037/0021-843X.109.3.504

40. Nolen-Hoeksema $S$ : Responses to depression and their effects on the duration of depressive episodes. Journal of Abnormal Psychology 1991; 100:569-582

41. Nolen-Hoeksema $S \&$ Morrow J: A prospective study of depression and posttraumatic stress symptoms after a natural disaster: The 1989 loma prieta earthquake. Journal of Personality and Social Psychology, 1991; 61:115-121

42. Pawlby S, Hay DF, Sharp D, Waters CS, O'Keane V: Antenatal depression predicts depression in adolescent offspring: prospective longitudinal community-based study. Journal of Affective Disorders 2009; 113:236-243

43. Rescorla L, Achenbach TM, Ivanova MY, Dumenci L, Almqvist $F$, Bilenberg $N$, et al: Behavioral and emotional problems reported by parents of children ages 6 to 16 in 31 societies. Journal of Emotional and Behavioral Disorders 2007a; 15:130-142. doi:10.1177/10634266070150030101

44. Rescorla LA, Achenbach TM, Ivanova MY, Dumenci L et al.: Epidemiological comparisons of problems and positive qualities reported by adolescents in 24 countries. Journal of Consulting and Clinical Psychology 2007b; 75:351-358
45. Roussos A, Francis K, Zoubou V, Kiprianos S, Prokopiou $A$, Richardson $C$ : The standardization of Achenbach's Youth Self-Report in Greece in a national sample of high school students. Eur Child Adolesc Psychiatry 2001; 10:47-53

46. Sandoval M, Lemos S, Vallejo G: Self-reported competences and problems in Spanish adolescents: a normative study of the Youth Self-Report. Psicothema, 2006; 18:804-809

47. Shapero BG, Hankin LB, Barrocas AI: Stress generation and exposure in a multi-wave study of adolescents: Transactional processes and sex differences. Journal of Social and Clinical Psychology 2013; 32:989-1012

48. Sheeber L, Davis B \& Hops H: Gender-specific vulnerability to depression in children of depressed mothers. In: Goodman SH, Gotlib IH, editors. Children of depressed parents: Mechanisms of risk and implications for treatment. Washington, DC: APA, 2002

49. Sloan E, Hall K, Moulding R, Bryce S, Mildred $H$ \& Staiger PK: Emotion regulation as a transdiagnostic treatment construct across anxiety, depression, substance, eating and borderline personality disorders: A systematic review. Clinical Psychology Review 2017; 57:141-163. doi:10.1016/j.cpr.2017.09.002

50. Snyder HR / Hankin BL: Spiraling out of control: Stress generation and subsequent rumination mediate the link between poorer cognitive control and internalizing psychopathology. Clin Psychol Sci 2016; 4:1047-1064

51. Snyder HR, Miyake A, Hankin BL: Advancing understanding of executive function impairments and psychopathology: Bridging the gap between clinical and cognitive approaches. Frontiers in Psychology 2015; 6:328. doi:10.3389/fpsyg.2015.00328

52. Strauman TJ \& Eddington KM: Treatment of depression from a self-regulation perspective: basic concepts and applied strategies in self-system therapy. Cognitive Therapy and Research, 2017; 41:1-15. doi:10.1007/s10608-016-9801-1

53. Svendsen JL, Kvernenes KV, Wiker AS, \& Dundas I: Mechanisms of mindfulness: rumination and self-compassion. Nordic Psychology 2017; 69:71-82.

https://doi.org/10.1080/19012276.2016.1171730

54. Watkins ER. Depressive rumination: investigating mechanisms to improvecognitive-behavioral treatments. Cogn Behav Ther 2009; 38:8-14

55. Watkins $E$ \& Brown RG: Rumination and executive function in depression: An experimental study. Journal of Neurology, Neurosurgery \& Psychiatry 2002; 72:400-2. doi: 10.1136/jnnp.72.3.400

56. Zanolie K \& Crone EA: Development of Cognitive Control across Childhood and Adolescence In: Ghetti S., editor. The Stevens' Handbook of Experimental Psychology and Cognitive Neuroscience, 4th edn, Vol. 4, New York: Wiley, 2018

Correspondence:

Sanja Jandrić, $M A, P h D$ candidate

Unit for Child and Adolescent Psychiatry, University Hospital Center Osijek

Europske avenije 14, HR-31 000 Osijek, Croatia

E-mail: jandric.sanja1@gmail.com 